\title{
Retrospective Outcome of 30 Patients Prenatally Diagnosed with Single Umbilical Artery
}

\author{
${ }^{\circledR}$ Gülenay GENÇOSMANOĞLU TÜRKMEN ${ }^{a},{ }^{\circledR}$ Zehra VURAL YILMAZ ${ }^{a},{ }^{\circledR}$ Pınar TOKDEMİR ÇALIŞa, \\ ${ }^{\circledR}$ Çağanay SOYSAL ${ }^{\text {a }}{ }^{\circledR}$ İrem TERIN ${ }^{a},{ }^{\circledR}$ Cemre ÇELIK $^{a},{ }^{\circledR}$ İsmail Burak GÜLTEKINa,

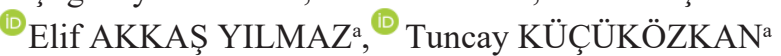

${ }^{a}$ Clinic of Gynecology and Obstetrics, University of Health Sciences Dr. Sami Ulus Maternity and Children's Training and Research Hospital, Ankara, TURKEY

\begin{abstract}
Objective: Single umbilical artery (SUA) in fetus have shown to be associated with structural anomalies, chromosomal disorders and growth restiction. In this study, we aimed to present the obstetric outcomes in fetuses with SUA. Material and Methods: In this retrospective study, obstetric results of 30 patients diagnosed with SUA over a 2-year period were analyzed. Results: There were 30 cases of prenatally diagnosed SUA. Twenty eight patients had singleton pregnancies and 2 had dichorionic diamniotic twin pregnancies. The gestational week at the time of diagnosis varied between 15 and 24 weeks, with the mean week of diagnosis at 21 weeks. Additional ultrasonographic findings accompanying the SUA were detected in 13 patients (43\%). Minor abnormalities (renal pelviectasia, choroid plexus cyst, persistant right umbilical vein) were detected in 4 patients in this group. More than one abnormality was detected in 7 fetuses. Structural abnormalities were distributed as follows: cardiovascular system abnormalities in 9 fetuses, musculoskeletal abnormalities in 3 fetuses, urogenital system abnormalities in 3 fetuses, central nervous system abnormalities in 4 fetuses and gastrointestinal system abnormalities in 2 fetuses. Chromosomal abnormalities were detected in 3 fetuses. Intrauterin growth restiriction was not detected in isolated SUA patients and also no chromosomal abnormality was detected in this group. Conclusion: Umbilical arteries of fetus should be checked during detailed ultrasound examination. Detailed fetal anatomic examination should include fetal echocardiography. During fetal echocardiography, fetal venous system must also carefully be examined.
\end{abstract}

Keywords: Single umbilical artery; prenatal diagnosis; perinatal outcome

Normal human umbilical cord contains 2 arteries and a single vein, as the right umbilical vein goes to atrophy during early fetal development. The single umbilical artery (SUA) is characterized by a vein and an artery in the umbilical cord, and more often it is the left artery that is absent. ${ }^{1}$ It is one of the most common malformations of the umbilical cord, occurring in one of 200 singleton pregnancies. ${ }^{2}$ It has been reported to occur 3-4 times more in twins compared to singleton pregnancies. ${ }^{3}$ Although its pathogenesis has not been clarified, 3 basic theories are widely accepted today: 1 . Primary agenesis of the umbilical artery, 2. Secondary atrophy or agenesis of the normally developing umbilical artery, and 3. Persistence of the original body stalk allantois artery. In some cases, even though both umbilical arteries were de- tected during the first trimester ultrasound evaluation, the second trimester ultrasound evaluation can show the absence of an umbilical artery. During the embryological evaluations of some fetuses with a SUA, the residue of an occluded second umbilical artery can be seen to further gain support for the validity of the second theory. ${ }^{3,4}$ Risk factors include assisted reproductive techniques, smoking, first pregnancy at a young age or multiparity at an advanced age. ${ }^{5,6}$

In English written literature, it has been shown that the risk of structural anomalies, chromosomal disorders and intrauterine growth restriction (IUGR) increases in fetuses with SUA. The most common malformations to occur have been reported in the cardiovascular, gastrointestinal and renal systems. Among chromosomal abnormalities, it has been

Correspondence: Gülenay GENÇOSMANOĞLU TÜRKMEN

Clinic of Gynecology and Obstetrics, University of Health Sciences Dr. Sami Ulus Maternity and Children's Training and Research Hospital, Ankara, TURKEY

E-mail: drgulenay@yahoo.com

Peer review under responsibility of Journal of Clinical Obstetrics \& Gynecology. 
shown that the incidence of trisomy 13 and 18 are especially higher. ${ }^{7-9}$ In this study, the obstetric outcomes of patients with SUA detected in the perinatology outpatient clinic of our department in the last two years were evaluated.

\section{MATERIAL AND METHODS}

This study was prepared in accordance with the Helsinki Declaration and this article was approved by the ethical committee of Ministry of Health Dışkap1 Yıldırım Beyazıt Training and Research Hospital (decision number 6.7.2020-91/11). Among the patients examined in the Perinatology Outpatient Clinic at University of Health Sciences Dr. Sami Ulus Maternity and Children's Training and Research Hospital, between the dates of 1.1.2018 to 1.1.2020, the ultrasonography results of 1601 patients in the system were scanned and 30 patients with a SUA were detected and included in this retrospective study. Parameters of age, gravida and parity, gestational age at diagnosis, presence of additional anomalies, amniocentesis results, birth weeks, and obstetric outcomes were obtained from the electronic database of our hospital. By performing a detailed ultrasound evaluation between the $18^{\text {th }}-22^{\text {nd }}$ weeks, a diagnosis of SUA was made to patients where the two arteries near fetal bladder could not be seen using a colour Doppler evaluation. The diagnosis for IUGR was made in fetuses with an estimated fetal weight below the $10^{\text {th }}$ percentile according to its gestational week.

\section{RESULTS}

Among 1,601 patients evaluated in our perinatology outpatient clinic, 30 patients were diagnosed with SUA, thus representing an incidence of $1.8 \%$. Out of 30 patients, 22 were the referred patients for detailed ultrasound evaluations, 1 patient was followed up at the outpatient clinic due to pre-gestational diabetes, 3 patients were referred due to high risk detection in screening tests and 1 patient was referred due to anhydramniosis at the $15^{\text {th }}$ weeks of pregnancy. One patient was evaluated in the outpatient clinic due to a cardiac anomaly and one patient was followed up with the diagnosis of an omphalocele. Twenty eight patients had singleton pregnancies and 2 had dichorionic diamniotic twin pregnancies. The gestational weeks at the
TABLE 1: Demographic features of pregnancies.

\begin{tabular}{|lc|}
\hline Demographic features & $\mathrm{n}$ (minimum-maximum) \\
\hline Maternal age & $29(19-43)$ \\
Gestational week at diagnosis & $21(15-23)$ \\
Multiple pregnancy & $2 / 30$ \\
Assisted reproductive techniques for pregnancy & $2 / 30$ \\
Isolated single umbilical artery & $16 / 30$ \\
\hline
\end{tabular}

time of diagnosis varied between 15 and 24 weeks, with the mean week of diagnosis at 21 weeks. The mean age of the patients were 29.5 (19-43). The average parity was $0.8(0-3)$. Isolated SUA was observed in 16 patients $(53.3 \%)$. The demographic characteristics of these patients are summarized in Table 1.

Additional ultrasonographic findings accompanying the SUA were detected in 13 patients. More than one abnormality was detected in 7 fetuses. Minor abnormalities (renal pelviectasia, choroid plexus cyst, persistant right umbilical vein) were detected in 4 patients. Cardiovascular system anomalies including portosystemic shunt, agenesis of ductus venosus, hypoplastic left heart, right aortic arch, double outlet right ventricle, atrioventricular septal defect (AVSD), muscular ventricular septal defect (VSD) were observed in 9 patients in total. Skeletal limb anomaly (one with rockerbottom feet, one with syrenomelia) was detected in 2 fetuses. Amniocentesis was performed in two patients who had multiple anomalies and trisomy 18 was detected. Postnatal trisomy 21 was detected in one patient who did not accept amniocentesis prenatally. While polyhydramniosis was observed in patients with trisomy 18 and omphalocele, anhydramniosis was detected in patient with syrenomelia due to renal agenesis. No other amniotic fluid abnormalities were observed in other patients. In 5 patients, gestational diabetes was detected in their follow-up controls. Preeclampsia developed in 3 patients. Among these patients, intrauterine loss due to placental abruption was observed at the $30^{\text {th }}$ week in one who was followed up for muscular VSD. IUGR was not observed in isolated SUA patients. IUGR was observed during the prenatal follow-up of those patients with the portosystemic shunt, ductus venosus agenesis and postnatal trisomy 21 . The mean birth week of patients with isolated SUA was 39.1. A patient with mul- 
TABLE 2: Gestational age at diagnosis, additional ultrasonographic findings, and outcomes of the fetuses with SUA.

\begin{tabular}{|c|c|c|c|c|c|c|}
\hline Case & $\begin{array}{c}\text { GA at diagnosis } \\
\text { (week) }\end{array}$ & $\begin{array}{l}\text { Ultrasound } \\
\text { findings }\end{array}$ & Karyotyping & $\begin{array}{l}\text { Obstetric } \\
\text { problems }\end{array}$ & $\begin{array}{c}\text { GA at delivery } \\
\text { (week) }\end{array}$ & Outcome \\
\hline 1 & 19 & Omphalocele, right aortic arch & - & Polihyramnios & 32 & Exitus \\
\hline 2 & 14 & Rockerbottom foot, club hand, choroid plexus cyst & Tri 18 & - & 18 & TOP \\
\hline 3 & 19 & Isolated SUA & - & - & 39 & Live birth \\
\hline 4 & 22 & Isolated SUA & - & - & 39 & Live birth \\
\hline 5 & 15 & Choroid plexus cyst & $46, X Y$ & GDM & 39 & Live birth \\
\hline 6 & 21 & Isolated SUA & - & - & 39 & Live birth \\
\hline 7 & 20 & Isolated SUA & - & - & 39 & Live birth \\
\hline 8 & 21 & Isolated SUA & - & GDM & 39 & Live birth \\
\hline 9 & 20 & Isolated SUA & - & PDM, di-di twin & 36 & Live birth \\
\hline 10 & 21 & Isolated SUA & - & - & 40 & Live birth \\
\hline 11 & 20 & Persistant right umbilical vein, muscular VSD & - & HT, ablatio placenta & 30 & Exitus \\
\hline 12 & 23 & Persistant right umbilical vein & - & - & 38 & Live birth \\
\hline 13 & 21 & AVSD, VM, renal pelvieactasia & Tri 21 & IUGR & 34 & Live birth \\
\hline 14 & 22 & DORV, omphalocele, renal pelviectasia & Tri 18 & - & 23 & TOP \\
\hline 15 & 18 & Isolated SUA & - & IVF & 40 & Live birth \\
\hline 16 & 18 & Isolated SUA & - & GHT & 38 & Live birth \\
\hline 17 & 21 & Portosystemic shunt & - & IUGR & 35 & Live birth \\
\hline 18 & 23 & Isolated SUA & - & GDM & 40 & Live birth \\
\hline 19 & 20 & Isolated SUA & - & - & 38 & Live birth \\
\hline 20 & 19 & Isolated SUA & - & GDM & 39 & Live birth \\
\hline 21 & 24 & Hypoplastik left heart sydrome, VSD & - & - & 39 & Exitus \\
\hline 22 & 28 & Isolated SUA & - & Preeclampsia & 36 & Live birth \\
\hline 23 & 19 & Choroid plexus cyst, renal pelviectasia & - & GDM & 39 & Live birth \\
\hline 24 & 23 & Isolated SUA & - & - & 37 & Live birth \\
\hline 25 & 21 & Isolated SUA & - & - & 40 & Live birth \\
\hline 26 & 22 & Agenesis of ductus venosus & - & IUGR, IVF, di-di twin & 31 & Live birth \\
\hline 27 & 20 & Isolated SUA & - & PDM & 34 & Live birth \\
\hline 28 & 19 & Isolated SUA & - & - & 41 & Live birth \\
\hline 29 & 23 & Isolated SUA & - & Cervical cerclage & 37 & Live birth \\
\hline 30 & 15 & Syrenomelia, renal agenesis & - & Anhydramniosis & 15 & TOP \\
\hline
\end{tabular}

GA: Gestational age; TOP: Termination of pregnancy; GDM: Gestational diabetes mellitus; PDM: Pregestational diabetes mellitus; HT: Hypertension; VM: Ventriculomegaly; DORV: Double outlet right ventricle; IVF: In-vitro fertilization; GHT: Gestational hypertension; SUA: Single umbilical artery; AVSD: Atrioventricular septal defect; VSD: Muscular ventricular septal defect; IUGR: Intrauterine growth restriction.

tiple anomalies and another diagnosed with hypoplastic left heart syndrome died neonatally, while two patients preferred termination of pregnancy. The gestational age at diagnosis, additional ultrasonographic findings, karyotyping results, birth weeks and birth results of these patients are summarized in Table 2. Structural abnormalities by organ system involved and chromosomal abnormalities detected in prenatal and postnatal period are listed in Table 3. Autopsy was recommended to families after termination of pregnancy and fetal loss, but could not be performed due to parents' refusal.
TABLE 3: Anomalies by the organ systems detected in pregnancies with single umbilical artery.

\begin{tabular}{|lc|}
\hline Organ system & Number \\
\hline Cardiovascular & 9 \\
\hline Musculoskeletal & 3 \\
\hline Urogenital & 3 \\
Cerebral & 4 \\
Gastrointestinal & 2 \\
\hline
\end{tabular}

\section{DISCUSSION}

In detailed ultrasonographic evaluation, imaging of the umbilical arteries is routinely recommended. ${ }^{10}$ 
When the vessels next to the fetal bladder are examined using the colour Doppler in a transverse section, the diagnosis of SUA can be easily made when both arteries are not displayed. ${ }^{11}$ The diagnosis of SUA can be made after 12 weeks. ${ }^{12}$ In our study, a patient with a high risk of trisomy $13 / 18$ at the $14^{\text {th }}$ week was the earliest diagnosis for a SUA.

SUA is seen in $0.08-1.9 \%$ of live births. ${ }^{4}$ It has been shown that fetuses with single umbilical arteries may have malformations and chromosomal disorders in all organ systems. Chromosomal abnormalities have been reported in $8-11 \%$ of fetuses with SUA. While among these abnormalities, trisomy 18 and 13 were the most common, trisomy 21 is thought not be associated. ${ }^{13}$ In our study, chromosomal anomalies were detected in 3 patients in total (10.3\%), and trisomy 18 was detected in 2 patients during the prenatal period. There are multiple fetal anomalies in the ultrasound evaluation of these patients. One of our AVSD patients with ventriculomegaly and renal pelviectasis did not accept amniocentesis in the prenatal period. This patient was shown to have trisomy 21 in the postnatal period. Chromosomal defect was not observed in the group with isolated SUA.

While SUA may be isolated, in published literature, it has been associated with fetal anomaly at a rate of $13-50 \%{ }^{7,14}$ In our study, the major anomaly rate is $27.5 \%$ and therefore is compatible with these publications. There are studies showing that the most common anomalies accompanying the SUA are cardiovascular system anomalies. ${ }^{15}$ In a study by Geipel et al., $102 \mathrm{fe}-$ tuses were followed up for SUA. The most common accompanying diagnoses were urogenital and cardiovascular system anomalies. ${ }^{1}$ In a study in which 23 cases of SUA were presented by Özgün et al. they reported 3 cases of genitourinary system anomaly and 3 cases with a cardiovascular system anomaly with SUA as the most common anomalies. ${ }^{16}$ Our study, compatible with published literature, has detected 9 patients with cardiovascular system anomalies. Venous system anomalies are present in 5 of these patients. Fetal echocardiography evaluation is recommended in cases with SUA; however, as our study shows that, fetal echocardiography should also include an evaluation of the venous system.
There are conflicting publications about IUGR in fetuses with SUA. In some studies, intrauterine growth retardation was observed more frequently in fetuses with SUA than in normal fetuses. ${ }^{6}$ Predanic et al., in their study reported that there was no significant correlation between a SUA and birth weight. ${ }^{17}$ In 2013, a metaanalysis performed by Voskamp et al. announced there was no statistically significant increase in IUGR in patients with isolated SUA. ${ }^{18}$ In our study, while there was no intrauterine growth retardation in the isolated group, 2 of the fetuses with IUGR had cardiovascular system anomalies and another fetus had trisomy 21 . In 2015, Xu et al. published in a metaanalysis that the risk of polyhydramnios and oligohydramnios were shown to increase in cases with isolated single umbilical arteries. ${ }^{19}$ In our study, polyhydramnios was observed in 2 patients with trisomy 18 and the patient who was followed up for omphalocele, but oligohydramnios or polyhydramnios was not observed in the isolated group.

\section{CONCLUSION}

In conclusion, the diagnosis of SUA can be made after the $12^{\text {th }}$ week of pregnancy and therefore, should always be examined in the detailed ultrasound evaluation. Detailed ultrasound examination should be performed in patients diagnosed with SUA during the prenatal period, and chromosomal examination should be recommended in the presence of additional anomaly. Detailed fetal anatomic examination should also include fetal echocardiography. In addition to the recommendations in literature, we strongly recommend the evaluation of the venous system while performing fetal echocardiography.

\section{Source of Finance}

During this study, no financial or spiritual support was received neither from any pharmaceutical company that has a direct connection with the research subject, nor from a company that provides or produces medical instruments and materials which may negatively affect the evaluation process of this study.

\section{Conflict of Interest}

No conflicts of interest between the authors and / or family members of the scientific and medical committee members or members of the potential conflicts of interest, counseling, expertise, working conditions, share holding and similar situations in any firm 


\section{Authorship Contributions}

Idea/Concept: Gülenay Gençosmanoğlu Türkmen, Zehra Vural

Yılmaz; Design: Gülenay Gençosmanoğlu Türkmen, Pınar Tokdemir Çalış; Control/Supervision: İsmail Burak Gültekin, Tuncay Küçüközkan; Data Collection and/or Processing: Gülenay Gençosmanoğlu Türkmen, Irem Terin; Analysis and/or Interpretation: Gülenay Gençosmanoğlu
Türkmen, Zehra Vural Yllmaz; Literature Review: Gülenay Gençosmanoğlu Türkmen, Çă̆anay Soysal; Writing the Article: Gülenay Gençosmanoğlu Türkmen, Cemre Çelik; Critical Review: Zehra Vural Yılmaz, Tuncay Küçüközkan; References and Fundings: Gülenay Gençosmanoğlu Türkmen, Elif Akkaş Yılmaz; Materials: Gülenay Gençosmanoğlu Türkmen, Pınar Tokdemir Çalış.

\section{REFERENCES}

1. Geipel A, Germer U, Welp T, Schwinger E, Gembruch U. Prenatal diagnosis of single umbilical artery: determination of the absent side, associated anomalies, Doppler findings and perinatal outcome. Ultrasound Obstet Gynecol. 2000;15(2):114-7. [Crossref] [PubMed]

2. Hua M, Odibo AO, Macones GA, Roehl KA, Crane JP, Cahill AG. Single umbilical artery and its associated findings. Obstet Gynecol. 2010;115(5):930-4. [Crossref] [PubMed]

3. Persutte WH, Hobbins J. Single umbilical artery: a clinical enigma in modern prenatal diagnosis. Ultrasound Obstet Gynecol. 1995;6(3):216-29. [Crossref] [PubMed]

4. Heifetz SA. Single umbilical artery. A statistical analysis of 237 autopsy cases and review of the literature. Perspect Pediatr Pathol. 1984;8(4):345-78. [PubMed]

5. Lilja GM. Single umbilical artery and maternal smoking. BMJ. 1991;302(6776):569-70. [Crossref] [PubMed] [PMC]

6. Burshtein S, Levy A, Holcberg G, Zlotnik A, Sheiner $E$. Is single umbilical artery an independent risk factor for perinatal mortality? Arch Gynecol Obstet. 2011;283(2):191-4. [Crossref] [PubMed]

7. Chow JS, Benson CB, Doubilet PM. Frequency and nature of structural anomalies in fetuses with single umbilical arteries. J Ultrasound Med. 1998;17(12):765-8. [Crossref] [PubMed]
8. Dagklis T, Defigueiredo D, Staboulidou I, Casagrandi D, Nicolaides KH. Isolated single umbilical artery and fetal karyotype. Ultrasound Obstet Gynecol. 2010;36(3):291-5. [Crossref] [PubMed]

9. Tülek F, Kahraman A, Taşkın S, Özkavukçu E, Söylemez F. Determination of risk factors and perinatal outcomes of singleton pregnancies complicated by isolated single umbilical artery in Turkish population. J Turk Ger Gynecol Assoc. 2015;16(1):21-4. [Crossref] [PubMed] [PMC]

10. American College of Obstetricians and Gynecologists. ACOG Practice Bulletin No. 101: Ultrasonography in pregnancy. Obstet Gynecol. 2009;113(2 Pt 1):451-61. [Crossref] [PubMed]

11. Jeanty P. Fetal and funicular vascular anomalies: identification with prenatal US. Radiology. 1989;173(2):367-70. [Crossref] [PubMed]

12. Rembouskos $G$, Cicero S, Longo D, Sacchini C, Nicolaides KH. Single umbilical artery at 11 14 weeks' gestation: relation to chromosomal defects. Ultrasound Obstet Gynecol. 2003;22(6):567-70. [Crossref] [PubMed]

13. Saller DN Jr, Keene CL, Sun CC, Schwartz $\mathrm{S}$. The association of single umbilical artery with cytogenetically abnormal pregnancies. Am J Obstet Gynecol. 1990;163(3):922-5. [Crossref] [PubMed]
14. Jauniaux $E$. The single artery umbilical cord: it is worth screening for antenatally? Ultrasound Obstet Gynecol. 1995;5(2):75-6. [Crossref] [PubMed]

15. Dane B, Dane C, Kiray M, Cetin A, Yayla M. Fetuses with single umbilical artery: analysis of 45 cases. Clin Exp Obstet Gynecol. 2009;36(2): 116-9. [PubMed]

16. Özgün MT, Türkyılmaz Ç, Başbuğ M, Kaya D, Batuhan C. Prenatal sonographic diagnosis of single umbilical artery: evaluation of 23 cases. Turkiye Klinikleri J Gynecol Obst. 2009;19(2):75-80

17. Predanic M, Perni SC, Friedman A, Chervenak FA, Chasen ST. Fetal growth assessment and neonatal birth weight in fetuses with an isolated single umbilical artery. Obstet Gynecol. 2005;105(5 Pt 1):1093-7. [Crossref] [PubMed]

18. Voskamp BJ, Fleurke-Rozema H, Oude-Rengerink K, Snijders RJ, Bilardo CM, Mol BW, et al. Relationship of isolated single umbilical artery to fetal growth, aneuploidy and perinatal mortality: systematic review and meta-analysis. Ultrasound Obstet Gynecol. 2013;42(6):622-8. [Crossref] [PubMed]

19. Xu Y, Ren L, Zhai S, Luo X, Hong T, Liu R, et al. Association between isolated single umbilical artery and perinatal outcomes: a metaanalysis. Med Sci Monit. 2016;22:1451-9. [Crossref] [PubMed] [PMC] 